\title{
Implantes imediatos: uma revisão de literatura
}

\author{
Immediate implants: a literature review
}

Implantes inmediatos: una revisión de literature

Lara Lais de Lima Monezi ${ }^{1 *}$, Ellen Morgana Carneiro Matos ${ }^{1}$, Rafaela Calaça de Moraes Corrêa ${ }^{1}$, Tayguara Cerqueira Cavalcante ${ }^{1 .}$

\section{RESUMO}

Objetivo: Realizar uma revisão da literatura para analisar a instalação e funcionamento dos implantes imediatos, ressaltando suas vantagens, desvantagens e indicações. Métodos: Para o embasamento teórico, foi realizada uma revisão de literatura, consultando artigos científicos nas bases de dados MEDLINE, PUBMED, LILACS, BIREME, SCIELO, EBSCO, tendo como descritores do Decs: Implantes dentários; Cirurgia bucal; Reabilitação bucal. Resultados: A Implantodontia é uma especialidade presente na odontologia que tem por objetivo reestabelecer a função mastigatória e estética de espaços edêntulos, através do fenômeno da osseointegração. Dentre as técnicas utilizadas nessa especialidade, podemos citar a instalação imediata de implantes em dentes recém-extraídos, utilizando assim, o próprio alvéolo remanescente para instalação do implante. Considerações Finais: Dessa forma, temos um tempo de tratamento reduzido, onde o paciente exibe um grau elevado de satisfação, uma vez que se eliminam as tensões psicológicas ao realizar o procedimento em uma única cirurgia, devolvendo a função e a estética de forma otimizada.

Palavras-chave: Implantes dentários, Cirurgia bucal, Reabilitação bucal.

\begin{abstract}
Objective: To review the literature to analyze the installation and operation of immediate implants, highlighting their advantages, disadvantages and indications. Methods: For the theoretical basis, a literature review was performed, consulting scientific articles in the MEDLINE, PUBMED, LILACS, BIREME, SCIELO, EBSCO databases, having as Decs descriptors: Dental implants; Oral surgery; Mouth rehabilitation. Results: Implantology is a specialty present in dentistry that aims to reestablish the masticatory and aesthetic function of edentulous spaces, through the osseointegration phenomenon. Among the techniques used in this specialty, we can mention the immediate installation of implants in newly extracted teeth, thus using the remaining socket for implant installation. Final Considerations: Thus, we have a short treatment time, where the patient exhibits a high degree of satisfaction, since the psychological tensions are eliminated when performing the procedure in a single surgery, optimizing the function and aesthetics.
\end{abstract}

Keywords: Dental implants, Oral surgery, Oral Rehabilitation.

\section{RESUMEN}

Objetivo: Revisar la literatura para analizar la instalación y operación de implantes inmediatos, destacando sus ventajas, desventajas e indicaciones. Métodos: Para la base teórica, se realizó una revisión de la literatura, consultando artículos científicos en las bases de datos MEDLINE, PUBMED, LILACS, BIREME, SCIELO, EBSCO, que tienen como descriptores Decs: implantes dentales; Cirugía oral; Rehabilitación bucal.

${ }^{1}$ Centro Universitário Cesmac, Maceió-AL. *E-mail: monezi_10@hotmail.com 
Resultados: la implantología es una especialidad presente en odontología que tiene como objetivo restablecer la función masticatoria y estética de los espacios edéntulos, a través del fenómeno de osteointegración. Entre las técnicas utilizadas en esta especialidad, podemos mencionar la instalación inmediata de implantes en dientes recién extraídos, utilizando así el encaje restante para la instalación del implante. Consideraciones finales: Por lo tanto, tenemos un tiempo de tratamiento corto, donde el paciente exhibe un alto grado de satisfacción, ya que las tensiones psicológicas se eliminan al realizar el procedimiento en una sola cirugía, optimizando la función y la estética.

Palabras clave: Implantes dentales, Cirugía oral, Rehabilitación oral.

\section{INTRODUÇÃO}

A estética do sorriso é algo que, cada vez mais é valorizada dentro da sociedade e, consequentemente da odontologia, sendo assim, quando o paciente procura ajuda profissional, devido a uma perda dentária, ele busca também, rapidez e eficiência. Com isso, a necessidade de implantar imediatamente após a extração do dente, busca atender a necessidade de resultados mais rápidos e as exigências estéticas (VIANA KC, 2017).

A reabilitação oral sofreu uma grande revolução quando foi apresentado o conceito de osseointegração como sendo uma conexão entre o osso vivo e a superfície de um implante de titânio. Em protocolos antigos, apenas os pacientes totalmente edêntulos eram contemplados e o procedimento era feito em duas etapas cirúrgicas: ocorria primeiramente a instalação dos implantes, que ficavam submersos por 3 a 6 meses para que houvesse a osseointegração e na segunda etapa, era realizada uma cirurgia para exposição dos implantes na cavidade bucal, para sustentar uma prótese fixa (BRANEMARK PJ, 1985).

Com as altas taxas de sucesso em pacientes desdentados totais, estudou-se a possibilidade de realizar a ossointegração em pessoas edêntulas totais. Com o passar do tempo e o avanço das técnicas cirúrgicas, estudos comprovaram que não há uma diferença significativa entre fazer implantes imediatos em duas etapas ou apenas em uma (ABRAHAMSSON I, et al., 1999).

O procedimento de implantes imediatos é um sucesso no que se refere a osso integração, clinicamente, diminui o número de cirurgias (extração e implante feitos em momento único). No entanto, para definir a indicação deste procedimento, deve-se levar em conta alguns fatores como, qualidade óssea, padrão da oclusão, hábitos parafuncionais e condições sistêmica do paciente (MIGUEL JR, et. al., 2006).

Um dos grandes desafios, para esta técnica, é a manutenção da estrutura periodontal e do osso de suporte. As técnicas pouco invasivas para exodontia e continuidade da integridade do tecido periodontal, com a inserção imediata de implantes, seguida de provisionalização imediata, têm se mostrado como uma excelente alternativa na preservação da arquitetura gengival (MATTOS TB, et al., 2016).

As próteses provisórias são essenciais no trabalho de reabilitação, principalmente em região anterior, pois tem grande valorização estética, por isso, deve-se considerar, durante sua confecção, a semelhança com o elemento perdido, cor e adaptação, bem como a saúde dos tecidos adjacentes (COMMAR BC, et al., 2017).

O objetivo desta pesquisa foi realizar uma revisão da literatura para analisar a instalação e funcionamento dos implantes imediatos, ressaltando suas vantagens, desvantagens e indicações, e dessa forma conhecer a técnica dos implantes imediatos, possibilitando proporcionar maior conforto ao paciente.

\section{METODOLOGIA}

Este trabalho é uma revisão de literatura sistemática quantitativa descritiva, e para elaboração foram consultados trabalhos de revisão e/ou pesquisa publicados em periódicos científicos em língua portuguesa e inglesa disponibilizados na base de dados Scielo, Pubmed, Scholar Google, Medline e Lilacs.

O período de estudo não houve corte temporal, sendo incluídos estudos pertinentes ao assunto citado, em função da importância dos mesmos para o entendimento do tema, assim como, pesquisas complementares 
em livros-texto, monografias, dissertações, teses e trabalhos disponíveis online. Foram descartados artigos não pertinentes aos assuntos.

\section{RESULTADOS}

\section{Processo de Osseointegração}

Entender a osseointegração e os processos que a envolvem é de fundamental importância quando falamos de implantação imediata. Esta, por sua vez, é a conexão entre o osso vital e implantes de titânio, sem a interferência de tecidos entre o implante e osso, sendo necessário apenas uma técnica cirúrgica adequada para o seu mantimento (ADELL R, et al.,1981).

\section{Vantagens e desvantagens dos implantes imediatos}

Na literatura é descrito que uma das vantagens dos implantes imediatos é o tempo de trabalho diminuído para o profissional e o tempo de tratamento que se torna menor para o paciente, onde também é visto uma alta taxa de sucesso deste procedimento (BARZILAY I, et al., 1996).

Quanto às desvantagens, pode-se citar a insuficiência de mucosa queratinizada e a falta de mobilidade do retalho, falhas que podem ser corrigidas através de alguns procedimentos cirúrgicos, como técnica de regeneração óssea guiada com membranas para preenchimento do espaço entre osso e o implante (DOUGLASS GL, MERIN RL, 2002)

Há também a possibilidade de imprevistos durante o processo de extração como: anquilose, fraturas, expansão durante a extração, maiores possibilidades de infecção e falhas na técnica, tudo isso inviabiliza a implantação imediata (DOUGLASS GL; MERIN RL, 2002; LINDHE J, 2008).

Com isto, é importante observar que a colocação de implantes requer um diagnóstico preciso, uma seleção criteriosa do caso, além de um alto nível de habilidade cirúrgica do profissional, aumentando assim as chances de sucesso (EVANS CD; CHEN ST, 2008).

\section{Diagnóstico e planejamento}

O diagnóstico e o planejamento dos implantes imediatos exigem uma maior atenção a história médica e odontológica do paciente, sendo realizados exame intraoral, fotografias clínicas, modelos de estudo, radiografias periapicais e panorâmicas e tomografia computadorizada das áreas onde serão instalados os implantes (BECKER W; GOLDSTEIN M, 2008).

Ao exame clínico deve-se observar as alterações na mucosa, as espessuras dos tecidos moles, bem como a palpação do sítio receptor, são importantes para um diagnóstico preciso, um planejamento adequado e consequentemente um bom resultado (LINDHE J, 2008).

É importante também mencionar a etapa final do planejamento, a confecção de guia cirúrgico, o que confere maior previsibilidade no posicionamento dos implantes (BECKER W, 2005).

\section{Indicações e contraindicações}

O processo de indicar ou não um implante dentário imediato requer uma avaliação médica e odontológica criteriosa, sobretudo a história dental do paciente, histórico de periodontite, perdas de elementos dentais, entre outros, são de grande importância neste momento (LINDHE J, 2008).

Pode-se considerar como indicações listadas como mais importantes: Uma boa saúde periodontal; dentes com cáries extensas, impossíveis de reparação; dentes com fraturas radiculares com histórico de tratamento endodôntico; elementos com reabsorção radicular; volumes ósseos suficientes para estabilizar o implante; dentes que não tiveram sucesso ao tratamento endodôntico; gengiva espessa, entre outros. (BECKER W; GOLDSTEIN M, 2008).

Já, segundo LINDHE J (2008), as contraindicações para o processo de implante imediato, são: Pacientes que passaram por processo de quimioterapia há menos de 24 meses, visto que as drogas utilizadas afetam 
a imunidade, consequentemente a cicatrização também; pacientes que passaram por radioterapia (cabeça e pescoço) há menos de 24 meses, pois aumenta as chances de desenvolvimento de osteorradionecrose; uso de bisfosfonatos, geralmente utilizados no tratamento de osteoporose, comprometem o processo de remodelação óssea; diabéticos descompensados, em razão do comprometimento da cicatrização e o aumento de riscos de infecção; Presença de infecções orais associadas ao biofilme e pacientes com histórico de complicações cirúrgicas.

\section{Processo cirúrgico}

O êxito da implantação imediata está diretamente ligado ao sucesso da exodontia, que deve ser feita da melhor forma possível, para se evitar a perda óssea, além disso, um processo de curetagem minucioso, afim de eliminar qualquer lesão e restos de ligamento periodontal, deve ser feito (SCHWARTZARAD D; CHAUSHU G, 1997).

Os principais critérios a serem respeitados durante a exodontia são: Preservação da papila interdental, utilização de um elevador fino, para preservação óssea, força controlada e aplicação da odontosecção quando necessário, curetagem minuciosa, afim de eliminar agentes patógenos; formação do coágulo, dando início aos primeiros estágios de cicatrização óssea e preenchimento adequado (BECKER W, 2005).

Após a exodontia, as paredes do osso alveolar devem ser alisadas para o repovoamento celular, através de curetas, que também tem a função de localizar as tábuas vestibular e palatina, onde será instalado o guia cirúrgico e ocorrerá a penetração da broca (BECKER W, 2005).

Baseando-se neste princípio, o sucesso da implantação está diretamente ligado aos processos cirúrgicos adotados, tanto na extração como no implante.

\section{Reabsorção alveolar $\mathbf{X}$ implantes imediatos}

Estudo realizado em cães por Araújo MG e Lindhe J (2005), mostrou que, após a extração dental, as paredes ósseas acabam reduzidas em espessura e altura, nesta pesquisa foi observado as paredes intraalveolar e extra- alveolar, onde foi possível perceber que, após a extração, a porção intra-alveolar é preenchida por uma crista óssea que, posteriormente é substituída por medula, constatando-se a reabsorção alveolar, mesmo com a aplicação de técnicas conservadoras na exodontia. Assim sendo, a reabsorção alveolar é comum e fisiológica, acontecerá após a exodontia, com ou sem implante.

\section{Sucesso dos implantes imediatos}

Estudos mostram que o sucesso de implantes imediatos, está diretamente relacionado com o sucesso das técnicas cirúrgicas. Diversos estudos analisam desde o pós-operatório, até uma importante fração de tempo, tendo como critérios: a ausência de mobilidade clínica, ausência de rádio lucidez peri-implantar, ausência de dor e sintomas clínicos persistentes e impossíveis de serem resolvidos e ausência de complicações mecânicas (ALBREKTSSON T, et al., 1986).

Corroborando com esta pesquisa Becker BE et al. (1998), realizaram um estudo com 134 implantes imediatos sem utilização de enxertos, a taxa de sucesso foi de $93,3 \%$ em 7 anos.

Em um estudo, BOTTICELLI D et al. (2008), obtiveram alta taxa de sucesso em implantes imediatos, durante $o$ intervalo de 5 anos, nenhum implante foi perdido.

Em um estudo comparativo RIBEIRO FS et al. (2008), analisaram oitenta e dois implantes, sendo quarente e seis implantes imediatos e triste e seis implantes convencionais, foram acompanhados por 40 meses, 3 implantes imediatos falharam e todos os implantes por técnica convencional, obtiveram sucesso.

É importante destacar que nos estudos citados, a seleção dos pacientes seguiu alguns critérios de inclusão, dentre estes, o mais comum foi a boa condição sistêmica do paciente, sem perda óssea, ausência de hábitos parafuncionais, periodonto saudável, oclusão estável e funcional, boa higiene oral, pacientes sem doenças sistêmicas ou compensados, não fumantes nem etilistas (RIBEIRO FS et al. 2008; BECKER BE et al. 1998). 


\section{Implantes Imediados}

Estudos comprovam que a técnica de implantes imediatos, mostra-se uma boa escolha para reposição de elementos dentais perdidos, com altas taxas de sucesso. Iniciada por SCHULTE et al. (1978), ainda hoje é uma técnica promissora, quando bem indicada, sua taxa de sucesso se assemelha à de implantes convencionais. (BARZILAY I et al., 1996; RIBEIRO FS et al., 2008).

Em um estudo realizado por BLOCK MS et al., (2009), cujo objetivo foi comparar implantes imediatos e implantes por meio de técnicas convencionais em relação a adaptação dos tecidos, houve uma diferença significativa na posição da margem gengival vestibular que estava posicionada em posição mais apical no grupo tardio, em comparação com o grupo imediato, mas em relação a posição da crista óssea a resposta foi semelhante após o tratamento.

Em acompanhamento 12 meses após exodontia, SCHROPP L et al. (2003), observaram mudanças significativas no sítio de extração, na ausência de implantes imediatos ou convencionais. Estes apontam o Implante Imediato como alternativa para preservação das estruturas ósseas.

Estudos estabelecem que a colocação de um implante imediato, não impede que a remodelação óssea ocorra (ARAUJO MG et al., 2005; BOTTICELLI D et al., 2008). Um acompanhamento de cinco anos após a implantação imediata, mostrou que o nível ósseo foi mantido ou melhorado (BOTTICELLI M et al., 2008).

Após a extração de um molar inferior, um implante foi instalado imediatamente e acompanhado por oito anos, o paciente não apresentou nenhum tipo de dor ou desconforto, ou qualquer reação adversa durante esses anos. Decorridos oito anos o implante demonstrou uma situação estável, que aliada ao exame radiográfico confirmam o sucesso do tratamento (ARAUJO MG et al., 2005).

Os implantes imediatos possuem como principal característica seu desempenho, demarcado pelas altas taxas de sucesso e diminuição no tempo de tratamento, são escolha segura e eficaz, quando bem indicados. Os fatores chave para o sucesso estão em observar a correta indicação e contraindicação, além de estabelecer diagnóstico e planejamento minucioso para reabilitação com os implantes imediatos.

\section{CONCLUSÃO}

O presente estudo permitiu concluir que, implantes imediatos estão diretamente associados a uma boa técnica cirúrgica, que reduza a possibilidade de perda óssea durante a exodontia, é uma técnica que apresenta bastante sucesso e é amplamente conhecida por apresentar uma significante diminuição no tempo de trabalho com bons resultados funcionais e estéticos. Os estudos apresentados nesta revisão de literatura mostram altas taxas de sobrevida dos implantes imediatos, ressaltando assim sua alta confiabilidade. $O$ emprego de implantes imediatos mostra-se uma alternativa viável para reposição de elementos dentais perdidos.

\section{REFERÊNCIAS}

1. ABRAHAMSSON I, et al. Peri-implant tissues at submerged and non-submerged titanium implants. J Clin Periodontol. V.26,n. 9, p. 7, 1999.

2. ADELL R, et al. A 15-year study of osseointegrated implants in the treatment of the edentulous jaw. Int $J$ Oral Surg, v. 10, n. 6, p. 387-416, Dec 1981.

3. ALBREKTSSON T, et al. The long-term efficacy of currently used dental implants: a review and proposed criteria of success. J Oral Maxillofac Implants, v. 1, n. 1, p. 11-25, Summer 1986.

4. ARAUJO MG, LINDHE J. Dimensional ridge alterations following tooth extraction. An experimental study in the dog. J Clin Periodontol, v. 32, n. 2, p. 212-8, Feb 2005.

5. BARZILAY I, et al. Immediate implantation of pure titanium implants into extraction sockets of Macaca fascicularis. Part I: Clinical and radiographic assessment. J Oral Maxillofac. Implants, v. 11, n. 3, p. 299-310, May-Jun 1996.

6. BECKER BE, et al. A prospective clinical trial of endosseous screw-shaped implants placed at the time of tooth extraction without augmentation. J Periodontol, v. 69, n. 8, p. 920-6, Aug 1998.

7. BECKER W. Immediate implant placement: diagnosis, treatment planning and treatment steps/or successful outcomes. J Calif Dent Assoc, v. 33, n. 4, p. 303-10, 2005.

8. BECKER W, GOLDSTEIN M. Immediate implant placement: treatment planning and surgical steps for successful outcome. Periodontol 2000, v. 47, p. 79-89, 2008. 
9. BLOCK MS, et al. Prospective evaluation of immediate and delayed provisional single tooth restorations. $\mathrm{J}$ Oral Maxillofac Surg, v. 67, n. 11 Suppl, p. 89-107, Nov 2009.

10. BOTTICELLI D. et al. Implants in fresh extraction sockets: a prospective 5-year follow-up clinical study. Clin Oral Implants Res, v. 19, n. 12, p. 1226-32, Dec 2008.

11. BRANEMARK PJ. Introduction to osseointegration. In Branemark PI, Zarb G, Albrektsson T (eds) : tissue-Integrated Prostheses, Chicago and Berlin - Quintessence, 1985

12. COMMAR BC, et al. Instalação de prótese provisória implantossuportada: relato de caso. Revista de Odontologia de Araçatuba. v.38, n.2, p. 32-35. Araçatuba - SP, 2017.

13. DOUGLASS GL, MERIN RL. The immediate dental implant. J Calif Dent Assoc, v. 30, n. 5, p. 362-5, 368-74, May 2002.

14. EVANS CD, CHEN ST. Esthetic outcomes of immediate implant placements. Clin Oral Implants Res, v. 19, n. 1, p. 73-80, Jan 2008.

15. LINDHE J. Tratado de periodontia clínica e implantologia oral. 4. ed. Rio de Janeiro (RJ): Guanabara Koogan, 2005.

16. MATTOS TB, et al. Reabilitação imediata em área estética em alvéolo com grande comprometimento ósseo. Full Dental Science, v.7, n.26, p. 35-40. 2016.

17. MIGUEL JR, et al. Implante imediato associado ao enxerto de tecido conjuntivo: relato de caso clínico. Revista da Associação Paulista de Cirurgia Dental, v.70, n3, p. 312-316. São Paulo - SP, 2016.

18. RIBEIRO FS, et al. Success rate of immediate nonfunctional loaded single-tooth implants: immediate versus delayed implantation. Implant Dent, v. 17, n. 1, p. 109-17, Mar 2008.

19. SCHROPP $L$, et al. Bone healing and soft tissue contour changes following single-tooth extraction: a clinical and radiographic 12-month prospective study. J Periodontics Restorative Dent, v. 23, n. 4, p. 313-23, Aug 2003.

20. SCHULTE W, et al. The Tubingen immediate implant in clinical studies. Dtsch Zahnarztl Z, v. 33, n. 5, p. 348-59, May 1978.

21. SCHWARTZ AD, CHAUSHU G. Placement of implants into fresh extraction sites: 4 to 7 years retrospective evaluation of 95 immediate implants. J Periodontol, v. 68, n. 11, p. 1110- 6, Nov 1997.

22. VIANNA KC. Instalação de implantes imediatos contíguos em região estética: relato de caso com 30 meses de acompanhamento. Revista da Faculdade de Odontologia, v.47. 2017. 